\title{
Dysglycaemia and the risk of acute myocardial infarction in multiple ethnic groups: an analysis of 15,780 patients from the INTERHEART study
}

\author{
H. C. Gerstein - S. Islam - S. Anand - W. Almahmeed - A. Damasceno - A. Dans • \\ C. C. Lang • M. A. Luna - M. McQueen - S. Rangarajan - A. Rosengren - X. Wang • \\ S. Yusuf
}

Received: 20 January 2010 / Accepted: 8 July 2010 /Published online: 14 August 2010

(C) Springer-Verlag 2010

\begin{abstract}
Aims/hypothesis Although diabetes is an established risk factor for myocardial infarction (MI), disease control may vary. $\mathrm{HbA}_{1 \mathrm{c}}$ is a reliable index of ambient glucose levels and may provide more information on MI risk than diabetes status.

Methods The relationship between $\mathrm{HbA}_{1 \mathrm{c}}$ levels in $\mathrm{MI}$ patients and controls who participated in the 52 country INTERHEART study was analysed.

Results In 15,780 participants with a $\mathrm{HbA}_{1 \mathrm{c}}$ value $(1,993$ of whom had diabetes), the mean (SD) levels for $\mathrm{HbA}_{1 \mathrm{c}}$ were $6.15 \%(1.10)$ in the 6,761 MI patients and 5.85\% $(0.80)$ in the control participants. After adjustment for age, sex and
\end{abstract}

H. C. Gerstein · S. Islam · S. Anand · M. McQueen •

S. Rangarajan $\cdot$ S. Yusuf

The Population Health Research Institute,

Hamilton Health Sciences and McMaster University,

Hamilton, ON, Canada

H. C. Gerstein $(\bowtie) \cdot$ S. Islam $\cdot$ S. Anand $\cdot$ S. Rangarajan $\cdot$

S. Yusuf

Department of Medicine, McMaster University,

Room 3V38, 1200 Main Street West,

Hamilton, ON L8N 3Z5, Canada

e-mail: gerstein@mcmaster.ca

W. Almahmeed

Division of Cardiology, Sheikh Khalifa Medical City,

Abu Dhabi, United Arab Emirates

\section{A. Damasceno}

Faculty of Medicine, Eduardo Mondlane University,

Maputo, Mozambique

\section{A. Dans}

Department of Medicine,

University of the Philippines College of Medicine,

Manila, Philippines nine major MI risk factors (including diabetes), higher $\mathrm{HbA}_{1 \mathrm{c}}$ fifths above the lowest fifth $\left(\mathrm{HbA}_{1 \mathrm{c}}<5.4 \%\right)$ were associated with progressively higher OR of MI, with OR for the highest $\mathrm{HbA}_{1 \mathrm{c}}$ fifth $(\geq 6.12 \%)$ being 1.55 (95\% CI $1.37-1.75)$. When analysed as a continuous variable after adjustment for the same factors, every $1 \%$ higher $\mathrm{HbA}_{1 \mathrm{c}}$ value was associated with $19 \%(95 \%$ CI 14-23) higher odds of MI, while every $0.5 \%$ higher $\mathrm{HbA}_{1 \mathrm{c}}$ was associated with $9 \%$ higher odds of MI (95\% CI 7-11). Concordant relationships were noted across subgroups, with a higher OR noted in younger people, patients without diabetes or hypertension, and those from some regions and ethnicities.

C. C. Lang

Division of Medical Sciences, University of Dundee,

Dundee, UK

M. A. Luna

Department of Medicine, University of Virginia,

Charlottesville, VA, USA

M. McQueen

Department of Pathology and Molecular Medicine,

McMaster University,

Hamilton, ON, Canada

A. Rosengren

Institute of Medicine, Sahlgrenska Academy,

Gothenburg, Sweden

X. Wang

Laboratory of Human Genetics,

Beijing Hypertension League Institute,

Beijing, China 
Conclusions/interpretation The $\mathrm{HbA}_{1 \mathrm{c}}$ value provides more information on MI odds than self-reported diabetes status or many other established risk factors. Every $1 \%$ increment independently predicts a $19 \%$ higher odds of MI after accounting for other MI risk factors including diabetes.

Keywords Case-control · Diabetes · Dysglycaemia . Glycated haemoglobin $\cdot$ Myocardial infarction

\section{Abbreviations \\ Apo Apolipoprotein \\ MI Myocardial infarction}

\section{Introduction}

Diabetes is a common chronic condition of increasing prevalence, which currently affects approximately 5\% of adults worldwide and up to $10 \%$ of adults in western populations [1-3]. An even larger proportion of individuals is affected by lesser degrees of dysglycaemia, including impaired glucose tolerance and/or impaired fasting glucose. Many epidemiological studies have reported that progressively higher fasting $[4,5]$ or post-load $[6,7]$ glucose or $\mathrm{HbA}_{1 \mathrm{c}}$ levels [8-10] predict a progressively higher incidence of cardiovascular outcomes. For example, in a recent large prospective epidemiological study of 10,032 individuals, in which only $2.4 \%$ (243) of participants had known diabetes and $5.5 \%$ (549) had either known diabetes or $\mathrm{HbA}_{1 \mathrm{c}} \geq 6.5 \%$, a $1 \%$ higher $\mathrm{HbA}_{1 \mathrm{c}}$ level above $5 \%$ predicted a $20 \%$ higher incidence of cardiovascular disease after controlling for diabetes and several cardiovascular risk factors [8]. Another epidemiological study [9] reported that a $1 \%$ higher $\mathrm{HbA}_{1 \mathrm{c}}$ predicted a $14 \%$ higher incidence of cardiovascular outcomes in people with diabetes and a $68 \%$ higher incidence in people without diabetes. Consistent with these observations is the high prevalence of dysglycaemia observed in people presenting with an acute myocardial infarction (MI). Thus, approximately two thirds of individuals presenting to a coronary care unit have diabetes, impaired glucose tolerance or impaired fasting glucose based on glucose tolerance testing [11, 12].

The INTERHEART Study was an international casecontrol study of MI conducted in 29,972 people in 52 countries [13]. This study reported that nine cardiovascular risk factors confer more than $90 \%$ of the populationattributable risk of MI globally. After accounting for other risk factors, self-reported diabetes was independently associated with an OR of 2.37 (95\% CI 2.07-2.71) and a population-attributable risk of $10 \%$. However, this is likely to be an underestimate of the importance of dysglycaemia as a risk factor for MI, as prevalent diabetes is often under- diagnosed and abnormal glucose values at the time of an MI may be dismissed as being due to stress and as not reflecting an underlying metabolic abnormality. Moreover, little is known about the relationship between MI and dysglycaemia in multiple ethnic groups and regions across the world.

At the time that the INTERHEART study was conducted, blood samples for $\mathrm{HbA}_{1 \mathrm{c}}$ levels were collected in approximately $50 \%$ of all participants. Here we report on whether $\mathrm{HbA}_{1 \mathrm{c}}$ level is a cardiovascular risk factor that is independent of self-reported diabetes status, as well as independent of age, sex and the other eight major global cardiovascular risk factors identified in the INTERHEART study. We also report on the relationship between $\mathrm{HbA}_{1 \mathrm{c}}$ level and risk of MI within subgroups of individuals defined by clinical characteristics, ethnicity or geographic region.

\section{Methods}

Participants The design and key results of the INTERHEART study have been previously published [13]. Briefly, this was a large, international, standardised case-control study of 15,152 MI patients and 14,820 controls. The patient group comprised people from 262 sites in 52 countries worldwide (webtable 1 available from http:// image.thelancet.com/extras/04art8001webtable1.pdf [13]), who were admitted within $24 \mathrm{~h}$ of their first acute MI. At least one sex- and age-matched control with no history of heart disease or exertional chest pain was recruited for each case. All participants provided informed consent. Both patient and control groups were interviewed and examined and asked to provide non-fasting blood samples.

Procedures Findings from structured questionnaires and physical examinations were transferred to the Population Health Research Institute at McMaster University and Hamilton Health Sciences in Hamilton, ON, Canada. The presence of diabetes and/or hypertension was based on selfreport and ethnic origin was self-identified. Any tobacco smoking within the prior 12 months was defined as current smoking. Waist and hip circumference were measured using a non-stretchable tape at the narrowest point between the costal margin and iliac crest, and at the level of the greater trochanter respectively. Thirds of abdominal obesity for men and for women were based on WHR. Cutpoints for each third for each sex were determined from the control data and were $\leq 0.83,0.84-0.90$ and $>0.90$ for women, and $\leq 0.90,0.91-0.95$ and $>0.95$ for men; abdominal obesity was defined as a measurement in the top third for each sex. Individuals were judged to be physically active if they were regularly involved in moderate (walking, cycling or 
Table 1 The prevalence of diabetes and high $\mathrm{HbA}_{1 \mathrm{c}}$ levels in MI patients and controls

\begin{tabular}{llll}
\hline Variable & Total & Cases & Controls \\
\hline$n$ & 15,780 & 6,761 & 9,019 \\
Diabetes & $1,993(12.6)$ & $1,293(19.1)$ & $700(7.8)$ \\
HbA $_{1 c} \geq 6.12 \%$ & $4,089(25.9)$ & $2,208(32.7)$ & $1,881(20.9)$ \\
$\quad$ With diabetes & $1,304(8.3)$ & $872(12.9)$ & $432(4.8)$ \\
$\quad$ Without diabetes & $2,785(17.6)$ & $1,336(19.8)$ & $1,449(16.1)$ \\
HbA $_{1 c} \geq 5.8 \%$ & $7,737(49.0)$ & $3,771(55.8)$ & $3,966(44.0)$ \\
$\quad$ With diabetes & $1,582(10.0)$ & $1,049(15.5)$ & $533(5.9)$ \\
Without diabetes & $6,155(39.0)$ & $2,722(40.3)$ & $3,433(38.1)$
\end{tabular}

Data are presented as $n(\%)$ unless stated otherwise

gardening) or strenuous (jogging, football and vigorous swimming) exercise for $\geq 4 \mathrm{~h}$ per week. Regular alcohol use was defined as self-reported consumption at least once per week. Daily consumption of fruits and vegetables was defined as daily intake of both.

Non-fasting blood samples were available in 21,508 (79\%) of MI patients and controls, and were analysed centrally as reported previously. Samples $(20 \mathrm{ml})$ were drawn within $24 \mathrm{~h}$ of symptom onset for two-thirds of the MI patients and after $24 \mathrm{~h}$ for the remainder; they were then centrifuged at $1,500 \mathrm{~g}$, separated and frozen at $-20^{\circ} \mathrm{C}$ to $-70^{\circ} \mathrm{C}$. At the same time, additional samples of whole blood were collected on filter paper specifically designed for analysis of capillary or venous whole-blood samples
[14]. $\mathrm{HbA}_{1 \mathrm{c}}$ was analysed centrally in Canada and China using a HPLC system (Variant II; Bio-Rad, Munich Germany) standardised to the Diabetes Control and Complications Trial assay. Both laboratories have received National Glycohemoglobin Standardization Program (NGSP) Level 1 certification for this method. The interassay imprecision for the low and high whole-blood and the low and high filter paper controls was less than $2 \%$. Fifths of $\mathrm{HbA}_{1 \mathrm{c}}$ were based on the distribution of $\mathrm{HbA}_{1 \mathrm{c}}$ levels in controls without a history of diabetes.

Apolipoproteins (Apo) A-1 and B were measured using a device (Hitachi 917; Roche Diagnostics, Mannheim, Germany) and the ApoB version 2 and ApoA-1 version 2 kits (Tina-quant; Roche). The same measurement kits and a Hitachi 911 analyser (Roche) were used in Beijing, China. The two laboratories were further standardised by measuring the same lot numbers of Precinorm and Precipath controls from Roche Diagnostics in every run. In every run of patient sample analyses in China, two study patients and two reference pool samples were measured from samples that had been previously analysed in the central core laboratory in Canada [15].

Statistical analyses The rate or mean value of risk factors within different fifths of $\mathrm{HbA}_{1 \mathrm{c}}$ (defined above) were calculated and tests for trends across fifths of $\mathrm{HbA}_{1 \mathrm{c}}$ for MI patients and for controls were done using the CochranArmitage test for categorical variables and the linear trend test for continuous variables.

Table 2 Distribution of risk factors in control participants across fifths of $\mathrm{HbA}_{1 \mathrm{c}}$ levels

\begin{tabular}{|c|c|c|c|c|c|c|}
\hline \multirow[t]{2}{*}{ Variable } & \multicolumn{6}{|c|}{ Fifths of $\mathrm{HbA}_{1 \mathrm{c}}$ levels (\%) } \\
\hline & $<5.4$ & $5.4-5.59$ & $5.6-5.79$ & $5.8-6.11$ & $\geq 6.12$ & $p$ value \\
\hline$N$ & 1,768 & 1,509 & 1,776 & 2,085 & 1,881 & \\
\hline Mean age (years) & $54.5 \pm 12.5$ & $55.7 \pm 12.3$ & $56.0 \pm 12.1$ & $58.2 \pm 11.8$ & $59.2 \pm 11.3$ & $<0.0001$ \\
\hline Men, $n(\%)$ & $1,384(78.3)$ & $1,168(77.4)$ & $1,419(79.9)$ & $1,565(75.1)$ & $1,309(69.6)$ & \\
\hline Women, $n(\%)$ & $384(21.7)$ & $341(22.6)$ & $357(20.1)$ & $520(24.9)$ & $572(30.4)$ & $<0.0001$ \\
\hline Diabetes, $n(\%)$ & $35(2.0)$ & $53(3.5)$ & $79(4.5)$ & $101(4.9)$ & $432(23.0)$ & $<0.0001$ \\
\hline Hypertension, $n(\%)$ & $307(17.4)$ & $300(19.9)$ & $384(21.7)$ & $567(27.3)$ & $539(28.7)$ & $<0.0001$ \\
\hline Current smoking, $n(\%)$ & $545(31.2)$ & $461(31.2)$ & $489(27.8)$ & $565(27.4)$ & $447(24.2)$ & $<0.0001$ \\
\hline Physically active $\geq 4$ h/week, $n(\%)$ & $322(18.2)$ & $295(19.6)$ & $371(20.9)$ & $445(21.4)$ & $329(17.5)$ & 0.89 \\
\hline Daily fruit and vegetable intake, $n(\%)$ & $701(40.3)$ & $629(42.3)$ & $732(41.8)$ & $885(43.0)$ & $861(46.5)$ & 0.0004 \\
\hline Alcohol use $\geq$ once/week, $n(\%)$ & $436(24.8)$ & $418(27.9)$ & $449(25.4)$ & $515(24.8)$ & $416(22.2)$ & 0.013 \\
\hline Abdominal obesity (WHR top 3rd), $n(\%)$ & $498(28.7)$ & $485(32.7)$ & $579(33.3)$ & $708(34.5)$ & $709(38.5)$ & $<0.001$ \\
\hline Mean BMI & $25.4 \pm 4.0$ & $25.9 \pm 4.1$ & $26.0 \pm 4.2$ & $26.1 \pm 4.1$ & $26.5 \pm 4.5$ & $<0.0001$ \\
\hline Mean ApoB/ApoA1 & $0.75 \pm 0.30$ & $0.78 \pm 0.26$ & $0.80 \pm 0.28$ & $0.82 \pm 0.30$ & $0.84 \pm 0.31$ & $<0.0001$ \\
\hline
\end{tabular}

Unless otherwise indicated, values are mean $\pm \mathrm{SD}$

$\mathrm{HbA}_{1 \mathrm{c}}$ categories were derived from dividing the non-diabetic control participants into five groups by quintiles. The denominator varies slightly by row and cell reflecting missing data

$p$ values are for significance of trend across fifths using Cochran-Armitage test 
The odds and $95 \%$ CIs of suffering a MI in the 2nd, 3rd, 4th and 5th highest fifths of $\mathrm{HbA}_{1 \mathrm{c}}$ compared with the lowest fifth, after controlling for other risk factors, were calculated using unconditional logistic regression as described previously [13], with case status as the dependent variable and fifth of $\mathrm{HbA}_{1 \mathrm{c}}$ as well as other risk factors as independent variables. The proportion of MI cases (and 95\% CIs) vs $\mathrm{HbA}_{1 \mathrm{c}}$ were plotted for: (1) all participants; (2) participants with no diabetes history; and (3) participants with no diabetes history and $\mathrm{HbA}_{1 \mathrm{c}}<6.5 \%$; plotting was done using cubic $\mathrm{B}$-spline fits with three $\mathrm{HbA}_{1 \mathrm{c}}$ knots: $5.5 \%, 6.0 \%$ and $6.5 \%$. ORs adjusted for age, sex, region and all of the INTERHEART risk factors (and 95\% CIs) were computed and plotted for each of the above groups using cubic B-spline fit and $\mathrm{HbA}_{1 \mathrm{c}} \leq 5.25 \%$ as a reference. Logistic regression was used to calculate the odds of being a MI case for every $1 \%$ higher $\mathrm{HbA}_{1 \mathrm{c}}$ level within various subgroups and after adjustment for other risk factors. Interaction terms were included as independent variables where appropriate. For models that adjusted for all of the INTERHEART risk factors [13], the risk factors were defined as: (1) history of diabetes; (2) history of hypertension; (3) smoking (classified as never, former or current); (4) daily fruit or vegetable consumption (classified as neither, fruits or vegetables, and fruits and vegetables); (5) WHR thirds according to sex; (6) regular physical activity; (7) regular alcohol use (defined as at least one drink/week); (8) ApoB and ApoA1 thirds; and (9) psychosocial factors based on an index using measures of depression, financial stress, locus of control, global stress and stressful events [16].

Statistical analyses were done using SAS version 9.1 (SAS, Cary, NC, USA). All statistical tests of hypotheses are two sided.

\section{Results}

Baseline characteristics of INTERHEART participants including self-reported diabetes status have been published previously [13]. An $\mathrm{HbA}_{1 \mathrm{c}}$ level was available in 15,780 participants (1,993 with self-reported diabetes), comprising 6,761 MI cases (42.8\%) and 9,019 controls $(57.2 \%)$ with mean (SD) $\mathrm{HbA}_{1 \mathrm{c}}$ levels of $6.15 \%$ (1.10) and 5.85\% (0.80) respectively. For 11,318 individuals, blood for $\mathrm{HbA}_{1 \mathrm{c}}$ measurement was either not sent to the central labs or could not be analysed. Compared with participants without $\mathrm{HbA}_{1 \mathrm{c}}$ value, MI patients and controls with an $\mathrm{HbA}_{1 \mathrm{c}}$ value had a slightly higher BMI and ApoB/ApoA levels. MI patients with an $\mathrm{HbA}_{1 \mathrm{c}}$ value had a $2 \%$ higher prevalence of diabetes and $2.4 \%$ lower prevalence of hypertension, while controls with an $\mathrm{HbA}_{1 \mathrm{c}}$ had a $4.6 \%$ higher prevalence of male sex, a $3.6 \%$ higher prevalence of hypertension and a $0.5 \%$ higher prevalence of smoking. As noted in Table 1 , 1,293 MI cases $(19.1 \%)$ and 700 controls $(7.8 \%)$ with an $\mathrm{HbA}_{1 \mathrm{c}}$ level had diabetes; however, 2,208 (32.7\%) MI cases and $1,881(20.9 \%)$ controls had $\mathrm{HbA}_{1 \mathrm{c}}$ levels in the top fifth $(\geq 6.12 \%)$ and $3,771(55.8 \%) \mathrm{MI}$ cases and 3,966 (44.0\%) controls had high $\mathrm{HbA}_{1 \mathrm{c}}$ levels $\geq 5.8 \%$. Interestingly, 1,336 cases $(19.8 \%)$ and 1,449 controls (16.1\%) had an $\mathrm{HbA}_{1 \mathrm{c}}$ level $\geq 6.12 \%$ with no history of diabetes, while 2,722 cases $(40.3 \%)$ and 3,433 controls $(38.1 \%)$ had an $\mathrm{HbA}_{1 \mathrm{c}}$ level $\geq 5.8 \%$ with no history of diabetes.

The distribution of cardiovascular risk factors in control participants across $\mathrm{HbA}_{1 \mathrm{c}}$ levels is shown in Table 2. Progressively higher $\mathrm{HbA}_{1 \mathrm{c}}$ levels were associated with increasing age $(p<0.0001)$, BMI $(p<0.0001), \mathrm{ApoB} /$
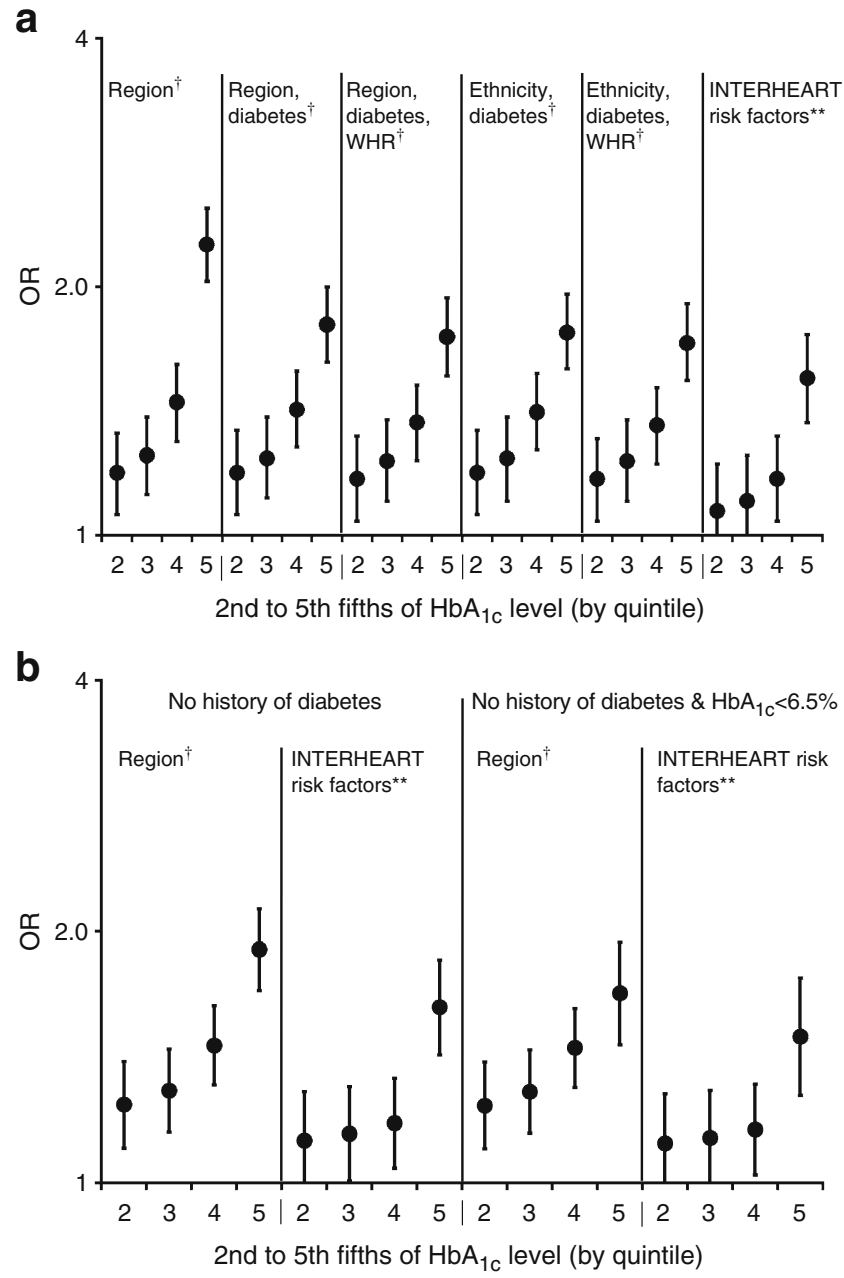

Fig. 1 The ORs $(95 \% \mathrm{CI})$ of having had an MI (i.e. being a case vs control) within each fifth of HbAlc level in comparison with the lowest fifth, after adjustment for age, sex and various groups of other covariates are shown for all participants (a) and for those without diabetes (b). The $p$ value for trend across fifths in each model was: ${ }^{* *} p=0.01$ and ${ }^{\dagger} p<0.0001$. $\mathrm{HbA}_{1 \mathrm{c}}$ categories based on quintiles in the control participants were $<5.4 \%, 5.4-5.59 \%, 5.6-5.79 \%, 5.8-6.11 \%$ and $\geq 6.12 \%$ 
ApoA1 levels $(p<0.0001)$. Proportionally more women $(p<0.0001)$, people with diabetes $(p<0.0001)$, hypertension $(p<0.0001)$, fruit and vegetable intake $(p=0.0004)$ and abdominal obesity $(p<0.001)$, as well as proportionally fewer smokers $(p<0.0001)$ and people with regular alcohol consumption $(p=0.013)$ also had progressively higher $\mathrm{HbA}_{1 \mathrm{c}}$ levels. No relationship with physical activity was noted $(p=0.9)$.

The odds of having suffered an MI vs control in higher $\mathrm{HbA}_{1 \mathrm{c}}$ fifths vs the lowest fifth after adjustment for age, sex and other risk factors for MI are illustrated in Fig. 1a for all participants and in Fig. 1b for participants without diabetes. Incrementally higher fifths of $\mathrm{HbA}_{1 \mathrm{c}}$ were significantly associated with higher odds of being an MI patient in all of the models assessed. Table 3 lists the adjusted odds of having an $\mathrm{MI}$ in: (1) the top four $\mathrm{HbA}_{1 \mathrm{c}}$ categories; and (2) the highest $\mathrm{HbA}_{1 \mathrm{c}}$ category in relation to the lowest $\mathrm{HbA}_{1 \mathrm{c}}$ category in all participants overall and within each geographical region, and in participants with no diabetes as well as in those with no diabetes and $\mathrm{HbA}_{1 \mathrm{c}}<6.5 \%$. Even after adjustment for all of the INTERHEART risk factors (including diabetes), people in the highest $\mathrm{HbA}_{1 \mathrm{c}}$ category were 1.55 times more likely (95\% CI 1.37-1.75) to have an MI than those in the lowest $\mathrm{HbA}_{1 \mathrm{c}}$ category; a similar estimate was observed for analyses that excluded people without diabetes and an $\mathrm{HbA}_{1 \mathrm{c}}<6.5 \%$.

The relationship between $\mathrm{HbA}_{1 \mathrm{c}}$ as a continuous variable and both the prevalence and odds of MI for all participants and for participants without evidence of prior diabetes is shown using spline models in Fig. 2. Figure 3 illustrates the estimate of the relationship between the risk of an MI and progressively higher $\mathrm{HbA}_{1 \mathrm{c}}$ levels. Thus, as noted in Fig. 3, every $1 \%$ higher $\mathrm{HbA}_{1 \mathrm{c}}$ level was associated with a $40 \%$ higher (95\% CI 35-45) odds of MI after adjustment for age, sex and region only, and with a $25 \%$ higher (95\% CI $20-30)$ odds of MI after additional adjustment for diabetes status. This progressive relationship persisted but was attenuated to $19 \%$ (95\% CI 14-23) after adjustment for all of the INTERHEART risk factors. When expressed per smaller increment in $\mathrm{HbA}_{1 \mathrm{c}}$, every $0.5 \%$ higher $\mathrm{HbA}_{1 \mathrm{c}}$ level was associated with an $18 \%$ (95\% CI 16-20), 12\% (95\% CI 10-14) and 9\% higher odds of MI (95\% CI 7-11) after adjustment for: (1) age, sex and region; (2) these variables plus diabetes status; and (3) these variables plus all of the remaining INTERHEART risk factors respectively. The relationship also persisted within subgroups defined by the presence or absence of each of the INTERHEART risk factors (Fig. 4a). Moreover, as noted in Fig. $4 \mathrm{a}$, there was a stronger association between $\mathrm{MI}$ and $\mathrm{HbA}_{1 \mathrm{c}}$ in people who were younger vs older ( $p=0.0001$ for heterogeneity), in the absence of a history of self-reported diabetes ( $p=0.009$ for heterogeneity) and in the absence of a history of hypertension ( $p=0.02$ for heterogeneity).

The $\mathrm{HbA}_{1 \mathrm{c}}$ level was progressively associated with the odds of MI throughout most regions and ethnicities (Table 3, Fig. 4b), although the strength of the relationship varied somewhat across groups $(p<0.0001$ for heterogeneity). Thus, as noted in Fig. $4 \mathrm{~b}$, the relationship between $\mathrm{MI}$ and $\mathrm{HbA}_{1 \mathrm{c}}$ was strongest in western Europe than in other regions, and strongest in people of European, Asian, South Asian and Arab ancestry compared with other ancestries.

Table 3 ORs $(95 \% \mathrm{CI})$ for $\mathrm{MI}$ and $\mathrm{HbA}_{1 \mathrm{c}}$ by region

\begin{tabular}{|c|c|c|c|c|c|c|c|}
\hline \multirow[t]{2}{*}{ Region } & \multirow{2}{*}{$\frac{\mathrm{HbA}_{1 \mathrm{c}}}{\text { Mean (SD) }}$} & \multicolumn{3}{|c|}{ Top $4 \mathrm{HbA}_{1 \mathrm{c}}$ categories vs lowest, adjusted for: } & \multicolumn{3}{|c|}{ Top $\mathrm{HbA}_{1 \mathrm{c}}$ category vs lowest adjusted for: } \\
\hline & & Age, sex & Age, sex $+\mathrm{IH}^{\mathrm{a}}$ & Age, sex $+\mathrm{IH}^{\mathrm{b}}$ & Age, sex & Age, sex $+\mathrm{IH}^{\mathrm{a}}$ & Age, sex $+\mathrm{IH}^{\mathrm{b}}$ \\
\hline Overall $^{\mathrm{c}}$ & $5.98(0.95)$ & $1.55(1.42-1.70)$ & $1.30(1.18-1.44)$ & $1.22(1.10-1.35)$ & $2.25(2.04-2.50)$ & $1.84(1.63-2.07)$ & $1.55(1.37-1.75)$ \\
\hline Western Europe & $5.93(0.72)$ & $1.47(1.01-2.12)$ & $1.26(0.82-1.93)$ & $1.19(0.77-1.83)$ & $2.07(1.36-3.14)$ & $2.01(1.24-3.26)$ & $1.72(1.06-2.81)$ \\
\hline Central/Eastern Europe & $5.87(0.79)$ & $1.91(1.47-2.48)$ & $1.56(1.17-2.07)$ & $1.46(1.10-1.95)$ & $2.32(1.68-3.20)$ & $1.62(1.13-2.31)$ & $1.31(0.91-1.87)$ \\
\hline Middle East/Egypt & $6.12(1.13)$ & $2.54(2.06-3.12)$ & $2.30(1.80-2.93)$ & $2.06(1.61-2.63)$ & $4.18(3.31-5.29)$ & $4.07(3.07-5.38)$ & $3.24(2.44-4.30)$ \\
\hline Africa & $6.00(0-73)$ & $1.78(1.07-2.95)$ & $1.05(0.58-1.87)$ & $1.01(0.56-1.83)$ & $1.82(1.05-3.14)$ & $0.91(0.48-1.71)$ & $0.86(0.45-1.64)$ \\
\hline South Asia & $6.00(0.87)$ & $1.29(0.97-1.72)$ & $1.07(0.77-1.48)$ & $1.00(0.72-1.39)$ & $1.79(1.29-2.47)$ & $1.44(0.99-2.10)$ & $1.25(0.86-1.83)$ \\
\hline China/Hong Kong & $5.98(1.07)$ & $1.11(0.94-1.31)$ & $0.94(0.79-1.13)$ & $0.93(0.77-1.12)$ & $1.60(1.31-1.95)$ & $1.31(1.05-1.62)$ & $1.20(0.96-1.49)$ \\
\hline SE Asia/Japan & $6.00(1.98)$ & $3.30(2.27-4.77)$ & $2.85(1.88-4.33)$ & $2.51(1.65-3.82)$ & $5.49(3.65-8.25)$ & $4.73(2.97-7.55)$ & $3.72(2.32-5.96)$ \\
\hline Australia/New Zealand & $5.83(0.52)$ & $0.94(0.51-1.74)$ & $0.96(0.49-1.89)$ & $0.91(0.46-1.78)$ & $1.46(0.72-2.96)$ & $1.41(0.65-3.08)$ & $1.26(0.58-2.75)$ \\
\hline South America/Mexico & $5.95(0.91)$ & $1.03(0.82-1.29)$ & $0.86(0.65-1.13)$ & $0.78(0.59-1.03)$ & $1.56(1.19-2.04)$ & $1.23(0.88-1.70)$ & $0.95(0.68-1.33)$ \\
\hline North America & $5.80(0.71)$ & $2.33(1.04-5.20)$ & $1.76(0.66-4.71)$ & $1.68(0.63-4.51)$ & $1.82(0.62-5.32)$ & $1.18(0.32-4.43)$ & $0.92(0.24-3.53)$ \\
\hline No DM & $5.83(0.76)$ & $1.46(1.34-1.61)$ & $1.25(1.13-1.39)$ & $\mathrm{N} / \mathrm{A}$ & $1.90(1.70-2.13)$ & $1.62(1.43-1.85)$ & N/A \\
\hline No $\mathrm{DM}+\mathrm{HbA}_{1 \mathrm{c}}<6.5 \%$ & $5.64(0.40)$ & $1.38(1.25-1.51)$ & $1.18(1.06-1.31)$ & $\mathrm{N} / \mathrm{A}$ & $1.69(1.46-1.94)$ & $1.50(1.27-1.76)$ & N/A \\
\hline
\end{tabular}

${ }^{a}$ INTERHEART risk factors (except diabetes); ${ }^{b}$ INTERHEART risk factors (with diabetes); ${ }^{c}$ overall estimates are also adjusted for region

DM, diabetes mellitus; N/A, not available 
Fig. 2 Spline plots of the per cent of cases and $95 \%$ CIs for all participants (a); participants with no diabetes history (b); and participants with no diabetes history and an $\mathrm{HbA}_{1 \mathrm{c}}<6.5 \%$ (c). Spline plots of ORs and $95 \%$ CIs adjusted for age, sex, region, and all of the INTERHEART risk factors are shown in panels $\mathbf{d}, \mathbf{e}$ and $\mathbf{f}$ for these three participant groups, respectively
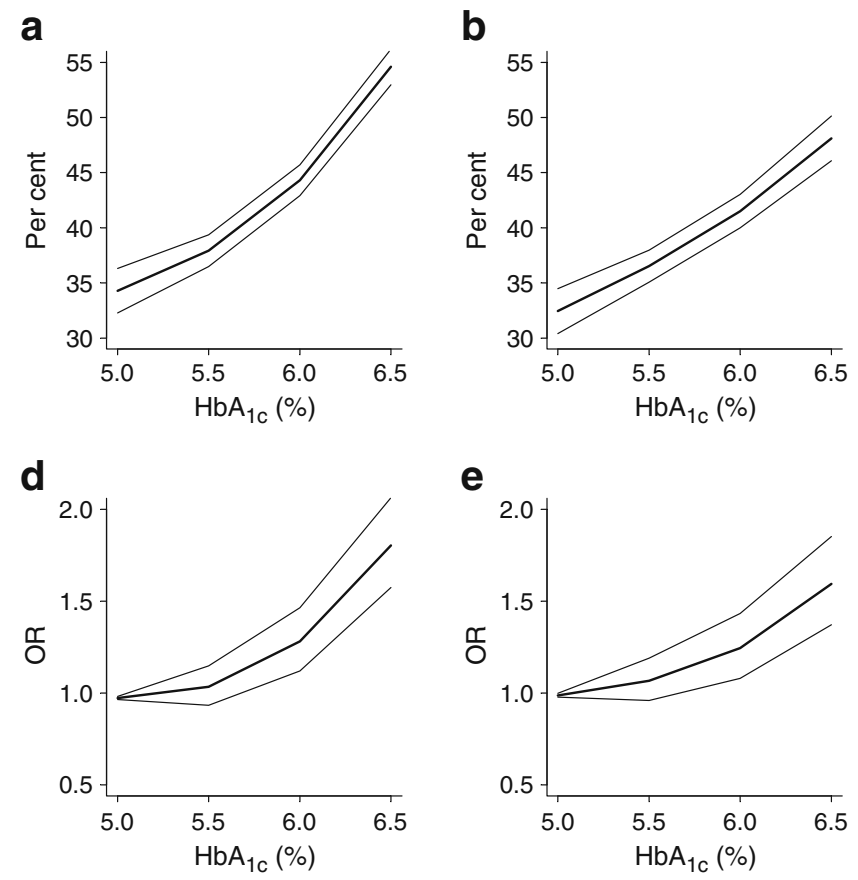

C

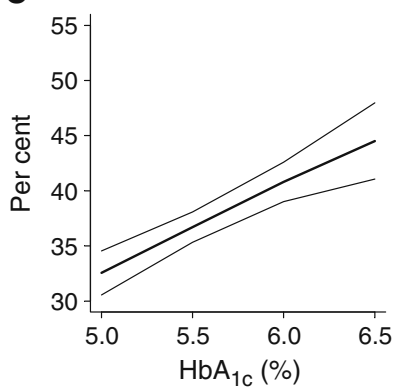

f

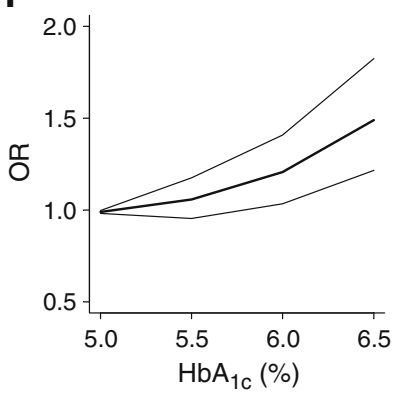

\section{Discussion}

This large global study of 15,780 people demonstrates that objective measurement of dysglycaemia (the $\mathrm{HbA}_{1 \mathrm{c}}$ ) is an independent cardiovascular risk factor within all regions of the world and within most ethnic groups. The observation that a $1 \%$ higher $\mathrm{HbA}_{1 \mathrm{c}}$ was associated with a $40 \%$ higher odds of MI after controlling for age, sex and region, and a $19 \%$ higher odds after controlling for all of the INTERHEART risk factors, including diabetes also demonstrates that self-reported diabetes underestimates the association between dysglycaemia and cardiovascular risk. The importance of dysglycaemia as a risk factor for MI in the general population is further highlighted by the finding that after accounting for age, sex, region and all of the INTERHEART risk factors including diabetes, an $\mathrm{HbA}_{1 \mathrm{c}}$ value of $\geq 5.4 \%$ was associated with a $22 \%$ higher odds of MI than a lower $\mathrm{HbA}_{1 \mathrm{c}}$. The observation of a $25 \%$ higher odds of MI in people with no history of diabetes and an $18 \%$ higher odds in people with both no diabetes history and an $\mathrm{HbA}_{1 \mathrm{c}}$ $<6.5 \%$ (Table 3) further highlights the relevance of these findings to the general population.

This analysis identified $\mathrm{HbA}_{1 \mathrm{c}}$ as an independent risk factor for $\mathrm{MI}$ in the presence of every other independent cardiovascular risk factor as determined by the INTERHEART study, and across most geographical regions and ethnicities. This, and the fact that the ORs remained significant after accounting for all of the INTERHEART risk factors without diabetes and were only slightly attenuated by including diabetes in the model, means that: (1) dysglycaemia increases cardiovascular risk through a

mechanism that appears to be independent of these other cardiovascular risk factors; and (2) that this mechanism is relevant with and without a history of diabetes, and operates on a global level.

These findings are consistent with the high prevalence of diabetes, impaired glucose tolerance or impaired fasting glucose observed in people presenting with a suspected MI $[11,12]$. As $\mathrm{HbA}_{1 \mathrm{c}}$ levels reflect chronic and not acute glucose elevation, these findings are also consistent with evidence that the abnormal glucose levels at the time of an MI reflect a prior underlying glucose-related abnormality

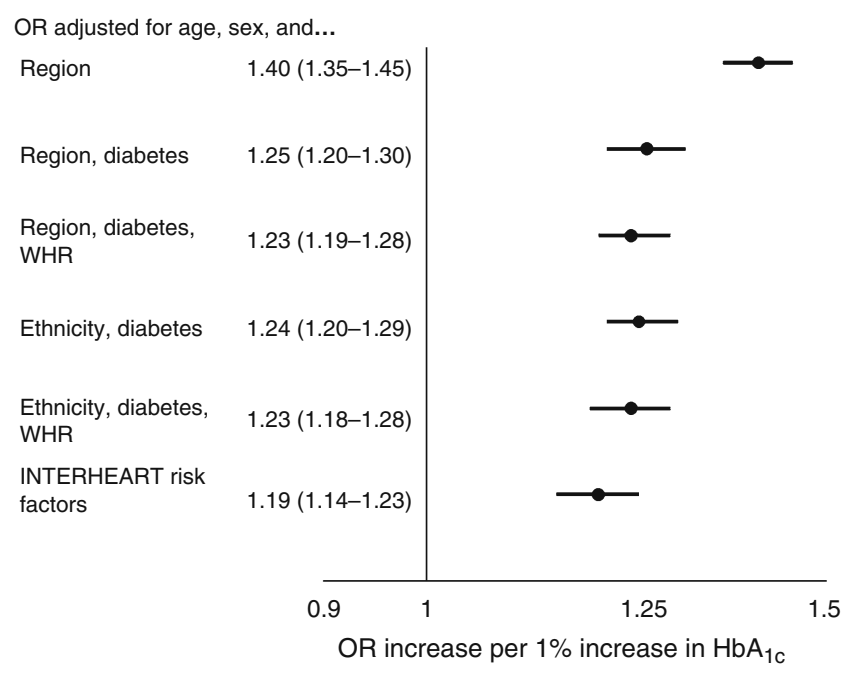

Fig. 3 ORs $(95 \% \mathrm{CI})$ of having had an MI (i.e. being a case vs control) for every $1 \%$ increase in $\mathrm{HbA}_{1 \mathrm{c}}$ after adjustment for age, sex and the other covariates as indicated 
Fig. 4 a Age-, sex- and regionadjusted ORs (95\% CI) of having had an MI (i.e. being a case vs control) for every $1 \%$ increase in $\mathrm{HbA}_{1 \mathrm{c}}$ within various subgroups. For WHR, the lowest, middle and highest thirds were $\leq 0.90,0.91-0.95$ and $>0.96$ for men $(\mathrm{M})$ and $\leq 0.83,0.84-0.90$ and $>0.90$ for women (W). The $p$ values are provided as evidence of heterogeneity across subgroups.

b Age- and sex-adjusted ORs $(95 \% \mathrm{CI})$ by geographic region and by self-identified ethnicity a

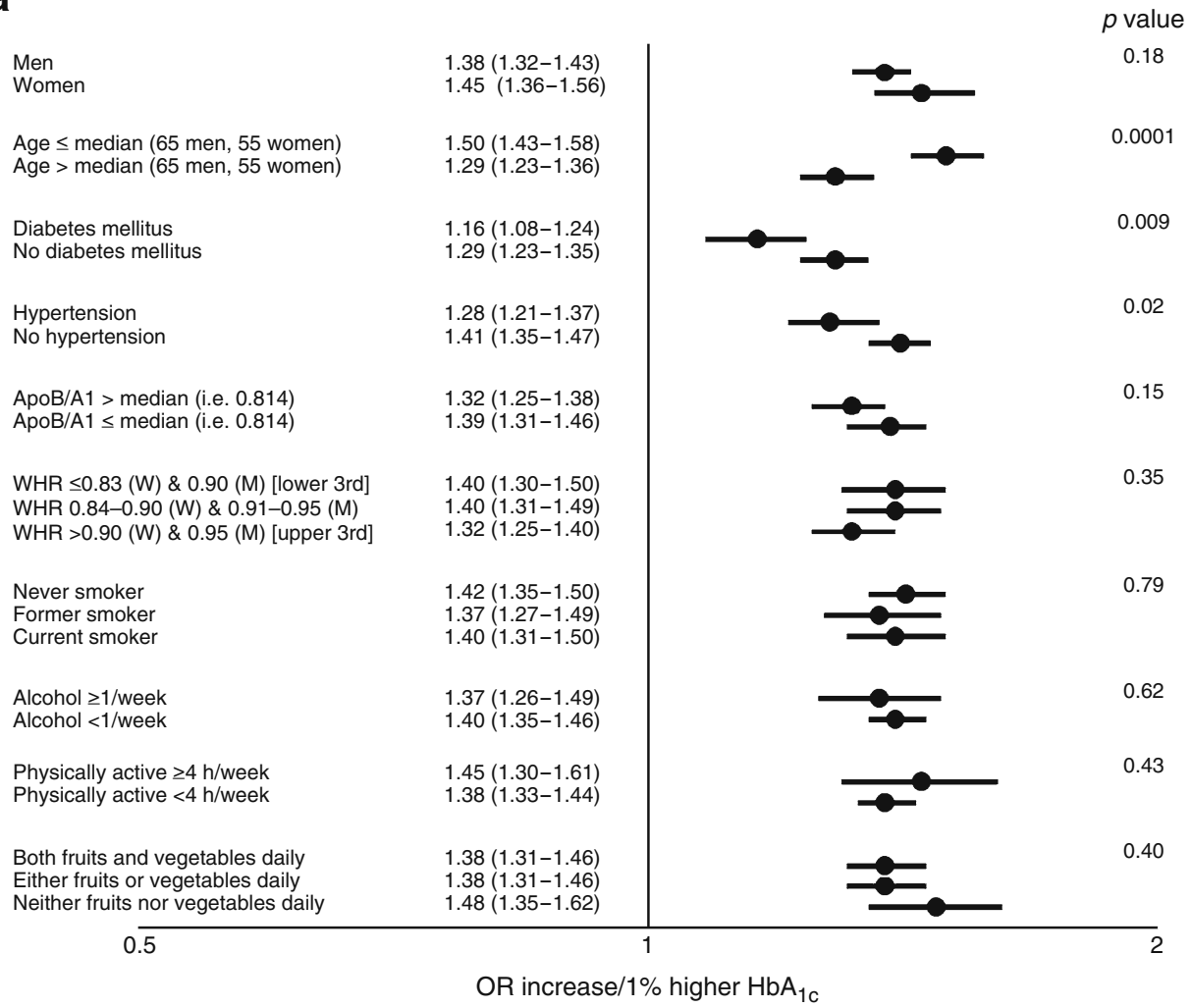

b
Western Europe

Central/Eastern Europe

Middle East/Egypt

Africa

South Asia

China/Hong Kong

Southeast Asia/Japan

Australia/New Zealand

South America/Mexico

North America

European

Chinese

South Asian

Other Asian

Arab

Latin American

Black African

Coloured African

Other

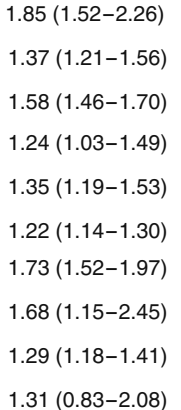

$1.50(1.37-1.66)$

$1.22(1.14-1.30)$

$1.47(1.34-1.62)$

$1.80(1.54-2.09)$

$1.54(1.41-1.67)$

$1.28(1.17-1.41)$

$1.44(1.12-1.84)$

$0.86(0.61-1.22)$

$1.41(1.35-1.47)$

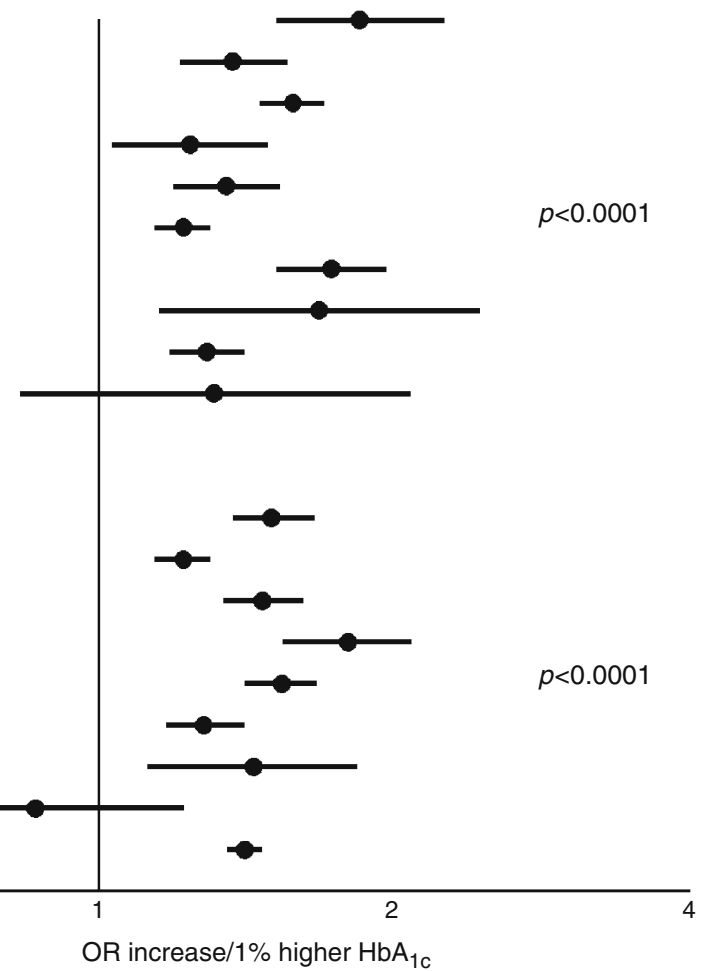


that was present before the event and are not just a response to the MI [17].

Consistent with other epidemiological analyses in the general population and in people with chronic heart failure $[9,10,18]$ a higher OR linked the $\mathrm{HbA}_{1 \mathrm{c}}$ value and $\mathrm{MI}$ in people with no history of diabetes vs those with such a history. Such an observation may be due to the use of $\mathrm{HbA}_{1 \mathrm{c}}$ as a therapeutic target in people with diabetes. This means that it reflects ambient glucose levels and the effects of treatment (which may modify the relationship between glycaemia and cardiovascular risk), whereas in people without diabetes (in whom $\mathrm{HbA}_{1 \mathrm{c}}$ levels are not typically measured) $\mathrm{HbA}_{1 \mathrm{c}}$ levels just reflect the impact of ambient glucose levels. Alternatively, people with a history of diabetes may receive other therapies that modify the relationship between the $\mathrm{HbA}_{1 \mathrm{c}}$ value and cardiovascular risk. The weaker relationship between $\mathrm{HbA}_{1 \mathrm{c}}$ and $\mathrm{MI}$ in the presence of other risk factors such as hypertension and older age, and the observation that adjustment for the INTERHEART risk factors attenuated, but did not eliminate the relationship suggests that these risk factors only partially assess similar underlying cardiovascular pathologies.

These findings are limited by the fact that they were cross-sectional in nature and that $\mathrm{HbA}_{1 \mathrm{c}}$ was not available in all participants. However, the strength inherent in its large sample size, its common approach for measuring cardiovascular risk factors globally and the availability of blood to analyse $\mathrm{HbA}_{1 \mathrm{c}}$ levels mean that these results are a robust estimate of the relationship between dysglycaemia and MI. It is possible that this relationship is due to confounding of dysglycaemia with unmeasured cardiovascular risk factors. However, the fact that it is independent of the INTERHEART risk factors (including self-reported diabetes) highlights its importance. Finally, it is not known whether therapies directed at lowering $\mathrm{HbA}_{1 \mathrm{c}}$ levels can affect prognosis in people presenting with a MI.

In summary, these findings clearly show that dysglycaemia as measured by the $\mathrm{HbA}_{1 \mathrm{c}}$ level in people with or without a history of diabetes is a strong, independent cardiovascular risk factor throughout different regions of the world and ethnicities. Overall, after accounting for the other major cardiovascular risk factors, for every $0.5 \%$ and $1 \%$ higher $\mathrm{HbA}_{1 \mathrm{c}}$ there was a $9 \%$ and $19 \%$ higher odds of MI respectively. The findings suggest that dysglycaemia is closely linked to an unmeasured causal factor, and that therapeutic and/or population-based strategies that reduce the prevalence of dysglycaemia by preventing or reversing diabetes, or by slowing the rise of $\mathrm{HbA}_{1 \mathrm{c}}$ with time may reduce the global burden of MI. Indeed, at least three large ongoing clinical trials are currently assessing the effect of preventing diabetes and/or of treating early diabetes on cardiovascular outcomes [19-21], and results from recently reported large trials of glucose lowering have suggested a $17 \%$ reduction in MI $[22,23]$ despite mixed effects on other cardiovascular outcomes including cardiovascular death. Regardless of the results of these and other clinical trials [24], the data presented here highlight the importance of the $\mathrm{HbA}_{1 \mathrm{c}}$ as an important and robust independent risk factor for $\mathrm{MI}$ in the presence and absence of a history of diabetes.

Acknowledgements The INTERHEART study was funded by the Canadian Institutes of Health Research, the Heart and Stroke Foundation of Ontario, and the International Clinical Epidemiology Network (INCLEN), as well as through unrestricted grants from several pharmaceutical companies (with major contributions from AstraZeneca, Novartis, sanofi aventis, Knoll Pharmaceuticals [now Abbott], Bristol Myers Squibb and KingPharma). It was also funded by various national bodies or companies in different countries: Chile: Universidad de la Frontera, Sociedad Chilena de Cardiologia Filial Sur; Colombia: Colciencias, Ministerio de Salud; Croatia: Croatian Ministry of Science and Technology; Guatemala: Liga Guatemalteca del Corazon; Hungary: Astra Hassle, National Health Science Council, George Gabor Foundation; Iran: Iran Ministry of Health; Italy: Boehringer-Ingelheim; Japan: Sankyo Pharmaceutical, Banyu Pharmaceutical, Astra Japan; Kuwait: Endowment Fund for Health Development in Kuwait; Pakistan: ATCO Laboratories; Philippines: Philippine Council for Health Research and Development, Pfizer Philippines Foundation, Astra Pharmaceuticals, the Astra Fund for Clinical Research and Continuing Medical Education, Pharmacia \& Upjohn; Poland: Foundation PROCLINICA; Singapore: Singapore National Heart Association; South Africa: MRC South Africa, Warner-Parke-Davis Pharmaceuticals, Aventis; Sweden: Grant from the Swedish State under LUA Agreement, Swedish Heart and Lung Foundation; Thailand: The Heart Association of Thailand, Thailand Research Fund.

Duality of interest The authors declare that there is no duality of interest associated with this manuscript.

\section{References}

1. International Diabetes Federation (2008) Prevalence Estimates of Diabetes 2007. Diabetes Atlas, 3rd edn. IDF, Brussels

2. Lipscombe LL, Hux JE (2007) Trends in diabetes prevalence, incidence, and mortality in Ontario, Canada 1995-2005: a population-based study. Lancet 369:750-756

3. Centers for Disease Control and Prevention (YEAR) Prevalence of diagnosed diabetes by age, United States, 1980-2005. Available from http://www.cdc.gov/diabetes/statistics/prev/natio nal/figbyage.htm accessed 13 June 2008

4. Lawes CM, Parag V, Bennett DA et al (2004) Blood glucose and risk of cardiovascular disease in the Asia Pacific region. Diab Care 27:2836-2842

5. Held C, Gerstein HC, Yusuf S et al (2007) Glucose levels predict hospitalization for congestive heart failure in patients at high cardiovascular risk. Circulation 115:1371-1375

6. Brunner EJ, Shipley MJ, Witte DR, Fuller JH, Marmot MG (2006) Relation between blood glucose and coronary mortality over 33 years in the Whitehall Study. Diab Care 29:26-31

7. DECODE Study Group EDEG (2003) Is the current definition for diabetes relevant to mortality risk from all causes and cardiovascular and noncardiovascular diseases? Diab Care 26:688-696

8. Khaw KT, Wareham N, Bingham S, Luben R, Welch A, Day N (2004) Association of hemoglobin A1c with cardiovascular 
disease and mortality in adults: the European prospective investigation into cancer in Norfolk. Ann Intern Med 141:413-420

9. Selvin E, Coresh J, Golden SH, Brancati FL, Folsom AR, Steffes MW (2005) Glycemic control and coronary heart disease risk in persons with and without diabetes: the atherosclerosis risk in communities study. Arch Intern Med 165:1910-1916

10. Gerstein HC, Swedberg K, Carlsson J et al (2008) The hemoglobin A1c level as a progressive risk factor for cardiovascular death, hospitalization for heart failure, or death in patients with chronic heart failure: an analysis of the Candesartan in Heart failure: Assessment of Reduction in Mortality and Morbidity (CHARM) program. Arch Intern Med 168:1699-1704

11. Bartnik M, Ryden L, Ferrari R et al (2004) The prevalence of abnormal glucose regulation in patients with coronary artery disease across Europe. The Euro Heart Survey on diabetes and the heart. Eur Heart J 25:1880-1890

12. Hu DY, Pan CY, Yu JM (2006) The relationship between coronary artery disease and abnormal glucose regulation in China: the China Heart Survey. Eur Heart J 27:2573-2579

13. Yusuf S, Hawken S, Ounpuu S et al (2004) Effect of potentially modifiable risk factors associated with myocardial infarction in 52 countries (the INTERHEART study): case-control study. Lancet 364:937-952

14. Stevenson T (1999) Glycosal: the first rapid, point-of-care test for the determination of hemoglobin A1c in patients with diabetes. Diabetes Technol Ther 1:425-431

15. McQueen MJ, Hawken S, Wang X et al (2008) Lipids, lipoproteins, and apolipoproteins as risk markers of myocardial infarction in 52 countries (the INTERHEART study): a case-control study. Lancet 372:224-233

16. Rosengren A, Hawken S, Ounpuu S et al (2004) Association of psychosocial risk factors with risk of acute myocardial infarction in 11119 cases and 13648 controls from 52 countries (the INTERHEART study): case-control study. Lancet 364:953-962

17. Norhammar A, Tenerz A, Nilsson G et al (2002) Glucose metabolism in patients with acute myocardial infarction and no previous diagnosis of diabetes mellitus: a prospective study. Lancet 359:2140-2144

18. Selvin E, Steffes MW, Zhu H et al (2010) Glycated hemoglobin, diabetes, and cardiovascular risk in nondiabetic adults. $\mathrm{N}$ Engl $\mathrm{J}$ Med 362:800-811

19. Origin Trial Investigators (2008) Rationale, design, and baseline characteristics for a large international trial of cardiovascular disease prevention in people with dysglycemia: the ORIGIN Trial (Outcome Reduction with an Initial Glargine Intervention). Am Heart J 155:26-32

20. Califf RM, Boolell M, Haffner SM et al (2008) Prevention of diabetes and cardiovascular disease in patients with impaired glucose tolerance: rationale and design of the Nateglinide And Valsartan in Impaired Glucose Tolerance Outcomes Research (NAVIGATOR) Trial. Am Heart J 156:623-632

21. Diabetes Trials Unit, University of Oxford. Acarbose cardiovascular cvaluation. Available from www.dtu.ox.ac.uk/index.php? maindoc=/ace/overview.php, accessed 27 October 2008

22. Ray KK, Seshasai SR, Wijesuriya S et al (2009) Effect of intensive control of glucose on cardiovascular outcomes and death in patients with diabetes mellitus: a meta-analysis of randomised controlled trials. Lancet 373:1765-1772

23. Mannucci E, Monami M, Lamanna C, Gori F, Marchionni N (2009) Prevention of cardiovascular disease through glycemic control in type 2 diabetes: a meta-analysis of randomized clinical trials. Nutr Metab Cardiovasc Dis 19:604-612

24. Gerstein HC (2009) Is it possible to reduce cardiovascular risk with glucose-lowering approaches? Nat Rev Endocrinol $5: 270-275$ 